\title{
Reflection on MOOC, Mini-Class and Flipped Class in College
}

\author{
Jing Xu \\ College of Information and Business, Zhongyuan University of Technology, Zhengzhou 450007, \\ China
}

\begin{abstract}
The year of 2012 is the world MOOC Year and the year of 2013 is the Chinese MOOC Year. MOOC, mini-class and flipped class have a wide application background under this time with a huge demand. With the development of the education and teaching reform, the amount of training class grows very fast. Since it is under the developing stage, there exists various problems in this kind of training course. This paper started with the relation between the development of information technology and the development of education and teaching, then the introduction of the development course of MOOC. It explained the differences among MOOC, mini-class and flipped class and top-quality course and network course, showing the foreseeable broad prospect, also putting forward with some countermeasures against a variety of problems in the training course.
\end{abstract}

Keywords: Massive open online course; Mini-class; Flipped class; Education and teaching reform; Information technology.

\section{The development of information technology and education and teaching reform}

\subsection{The influence of technology on the education and teaching}

In the earliest time, human beings used ropes for recording. Then after the invention of words, human began to record information in bamboo slips. And Confucius was lecturing his knowledge with inquiry-based teaching and discussion-based teaching, and Socrates with talk-based teaching. However, the information transmitted in these teaching methods were limited. Then the invention of printing made the popularization of knowledge. And Yuelu Academy, the first college in China, was founded in the ninth year of the Open Treasure of Northern Song Dynasty (AD 976), and Siena University was founded in the West in AD1200. With the advent of digital and information age, teaching stepped into the digital age. In the year of 2000, online university was born. However, there were many problems in this transformation method aimed at receiving degrees, and the phenomenon of false online education with true degree emerged endlessly. Then Tsinghua University and Renmin University of China and other universities stopped remote online education. Today, we are living in the era of the Internet+, cloud, big data, fragmentation and micro (Weibo, WeChat, micro film, micro shop), in which the amount of information is growing in geometric series. In the year of 2012, the age of the Internet had brought "MOOC" and made it popular very quickly to spread all over the world. According to the New York Times, the year of 2012 was called the First "MOOC" Year. In this year the three platforms of Udacity, Coursera and Edx had drove the MOOC movement, covering all the world, with the involvement of more than 200 universities. During the Edx Global Forum from Nov.19, 2014 to Nov. 22, 2014, U.S. President Barack Obama announced that Edx, one of the big three international MOOC platforms, formally joined the Connect ED Program, that middle school students could learn more than 40 courses on the Edx platform freely, and the Edx cooperation universities (MIT, Berkeley, etc.) had set up tutorial courses for the AP test, which indicated that MOOC began to serve for the whole country.

\subsection{The influence of information technology on Chinese curriculum construction}

The term MOOC originated from Canada in 2008, and developed in Silicon Valley in the United States. It began to emerge in China in 2012, and developed to large-scale in 2013. Therefore, the year of 2013 could be called the First MOOC Year of China, or the First Mini-class Year of China. In this year, the MOOC credits, MOOC curriculum, MOOC platform, School online, Good University online, MOOC of Tsinghua University, MOOC of Peking University, MOOC of Shanghai Jiao Tong University, Chinese University, Wisdom Tree, Flipped teaching, Flipped class, and Mini-class and other keywords had sprung up. 
There was similar development to the development of MOOC in China, but not much the same with the MOOC. The development of information technology was always combined with the curriculum construction in China. In the 1990's, multimedia teaching reform was performed and the multimedia classrooms were built up, continuing until now. In 2000, excellent courses emerged in the construction of open courses, and the recorded classroom was under construction. In 2008 emerged the video courses and the open class of HD recorded video courses. But these courses had not been accepted by students on a large scale. In 2012, MOOC was born in China, with the studio. According to relevant data statistics, by 2020 global MOOC will reach 50000 courses, shown in Figure 1 below. Chinese MOOC will soar over the next three years, according to the File of Institution of higher learning of the Ministry of Education [2015] No. 3: the excellent course of MOOC will be identified by 2007 , and reach to 3000 courses by 2020 . And the courses will be managed by the Ministry of Education and the public serving platform be selected out to run the MOOC. And 300,000 school-level courses of SPOC will be built up, as well as 30,000 province-level MOOCs and 3,000 national-level MOOCs (Fig. 1).

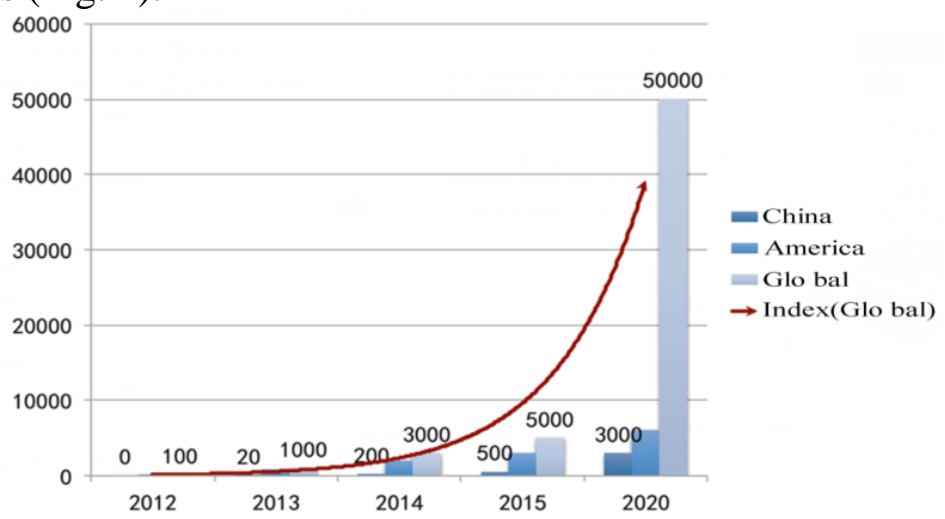

Statistics: Institute of MOOC of Shanghai Jiao Tong University in July 2015

Fig. 1 The predication of the number of the global MOOC in five years

\section{If MOOC, mini-class and flipped class will repeat the way of online university}

MOOC, mini-class and flipped class are much similar to the former online university, excellent courses and open class and education and teaching reform, which are all born on the basis of the development of information technology. Therefore, many people are wondering whether they will last for a short time as the online university or like the excellent courses exist in name only. However, the education and teaching reform and the construction management of new curriculum of the Ministry of Education are much different from the former. Below are the reasons that MOOC, mini-class and flipped class will develop in full swing.

\subsection{Demand of reality different from the former}

(1) Demand form lower layer to higher layer

The former construction of excellent courses and open class were often promoted by the government and famous teachers from top to the bottom. However, MOOC, mini-class and flipped class were different, as they were driven by the demand of the mass learners. According to the statistics of Shanghai Jiao Tong University, among the 30,000,000 students there were 5,000,000 who learned MOOC. The demand from the lower layer to the upper would be inestimable in the future. In the foreign countries, most of the MOOC learners were in hired, while in our country, the major were students, whose demand drove the constructors to transform the resource distribution model, to meet the demand from the lower layer to the upper layer. The government had already seen this kind of demand, strengthening the encouragement of teachers to explore the learning methods and teaching model of mobile and online learning of the MOOC, mini-class and flipped class, taking various measures to encourage teachers to try Mini-class teaching (competition for the mini-class teaching). Thus the demand of the students and the mass learners would be met, and the utilization and teaching efficiency would be improved. 
(2) The front-line teachers as the middle layer need reforming

The front-line teachers stand in the middle level, with demand of mass new generation learning and requirement from the government and the school, facing double pressure and acting as the main force of this education and teaching reform, which is a challenge and an opportunity. They must change the former online class and excellent course with the promotion of government, guidance of famous teachers, high cost, much support, high technical barriers, low participation of teachers, no focusing content, worse usability, low efficiency, non-popularization into a new teaching model with low technical barriers, low cost, popularization to all the folks, easy development and usage.

\subsection{Profound age background}

(1) Internet + , the catalyzer

In the year of 2015, Internet+ hit many industries, such as the Internet+ Automobile hit the Taxi industry, the Internet+ Finance hit the liner business of the bank, Internet+ Shopping hit shopping mall, Internet + Social impacts the face-to-face communication, the Internet +TV hit The State Administration of Radio Film and Television (SARFT). Then what will be Internet +education like? The hit may be not as strong as those industries, but sooner or later it will be inevitable to hit at a certain degree. Meanwhile, we shall notice there are some differences from those industries, and internet+education is not exactly the same with the education+internet, the former is the transform of internet to education, the latter is the reform of education itself, and also the internet+education is not the same with MOOC. Whatever, internet and MOOC can not be divided, internet is the catalyzer of the production of MOOC, mini-class and flipped class.

(2) Matching with the demand of the new generation

We live in an era of diversity: the information age, the internet age, the digital age, the cloud age, the big data age, the knowledge and economy age, the reform times, micro study times, fragmentation times, personalized era. In such an era, what are the clear features of the new generation? Xiaojun Zheng, acting as the new generation teacher in the Digital bridge and digital age, put forward that the new generation were the aborigines of the digital, while their parents and teachers were digital immigrants or refugees. Meanwhile, the new generation is the I-generation, that is grown under the internet environment, self-center-generation, interaction not passivity, enjoying the E-life Style (online learning, Online Socializing, online entertainment, online shopping etc.). The new generation is also the non-mainstream generation, personalization, screen-slave, internet generation etc. The features of the new generation drive the front-line teachers to improve themselves by using the new media and new technology. And MOOC, mini-class and flipped class is the reform with the most attractiveness to the new generation.

\subsection{Broad usage background}

(1) Becoming the new favorite

The outstanding advantages of MOOC, mini-class and flipped class had made themselves became the new favorite of the learners, teachers and resource builders in the internet age. The sudden rise of MOOC enlarged the demand of the mini-class. The education value and application of mini-class were extended by the cloud computing, mobile internet and large data technology. The construction of the flipped class was promoted by the unique learning style and personalization demand of the new generation.

(2) Influence on the curriculum construction of the nationwide college in the future

From the year of 2012 to 2015, during the short three years MOOC had experienced the progress from birth to blossom extending to various schools all over country. Relevant government departments also had held a national mini-class group of multimedia course ware competition, the first university mini-class competition etc. And various local government or departments or schools had held mini-vedio competition and the construction of mini-class learning platform and so on. By now, MOOC, mini-class and flipped class are still under rapid developing. Our country planned to set up 300,000 school-level SPOC, 30,000 province-level MOOC and 3,000 state-level MOOC by 2020. MOOC, mini-class and flipped class are influencing the national construction for a long time in the future, as well as the education and teaching in various college. 
It can be seen that this education and teaching reform is very different form the former, in that, it has a massive root and era background, a developing prospect different from the excellent course and online universities, which won't repeat their old way or last only for a very short time.

\section{The present problems of the MOOC, mini-class and flipped class in college}

In 2014, not less colleges had employed professors to train the teachers for the MOOC, mini-class and flipped class. And most of the teachers understood the concept and new teaching methods, but without clearness or not paid enough attention. After that, with various competitions of this mini-class in the nationwide, more and more people began to focus on this research. And this training class also emerged endlessly. In May 2015, in Zhengzhou, I took part in the Training class of core teachers on the development, production and application of mini-class in college sponsored by the Research Association of Teacher Development of China Higher Education and co-organized by Educational Counseling Center of China Education Online. In July 2015, in Dalian, I joined the Quick Technology Training Class of New Concept of Mini-class sponsored by China Teachers and Education Service Center. And in November, in Zhengzhou, I took part in the the Second National Operation Practical Training Class of MOOC, mini-class and flipped class held by Academic Exchange Center of China Association of Experts and Scholars, Duxing Education Group, the Management Office of the National Teacher Special Scientific Research of Chinese Teachers Development Foundation and the general research group of the The National Innovative Teaching Methods and Innovative Teacher Training Research. From all these training class, I deeply understood the MOOC, mini-class and flipped class and found out many present problems after exchanging with learners from all over the country.

\subsection{Non-specific training objects}

Since the training objects were very different in the age, major, understanding level of the MOOC, mini-class and flipped courses. However, all these problems were out of the consideration of the Conference Affairs obviously with the only focus on the nationwide college and university teachers. During the training those teachers who learned Software, Urban planning and Interior Design etc. had the feeling that it was too easy, it was no use talking the software all the time. While the elders without good knowledge of computer did not get one software. Therefore, the training objects were not specific, and the training was not targeted.

\subsection{The introduction of MOOC not focused on one certain course}

The three training were all on the MOOC, mini-class and flipped class, with the cites of the rather good videos of various majors at home and abroad as the case study which were talked rather wide, without focusing on one certain major or course on the introduction of MOOC, mini-class and flipped class. The students usually did not take good use of these training classes.

\subsection{The trainers with some special purposes}

Trainers were very serious during the training with full preparation, and the training objects were actively to come up with relative questions, from which the learner gained a lot. However, during my three training, the first training teacher got the first prize of the nationwide mini-class. The other two were training with some special purposes, one was trying to recommend his text books, the other was promoting the MOOC platform of his own school.

\subsection{The training objects payed much attention on how to produce MOOC}

Both the training teachers and the training students took it very serious. During the training, when it came to the application and installation of soft wares, such as Camtasia Studio, deep zoom of Focusky, 3D page-turning PageFlip Standard, Inpain, Snagit, Quizcreator, Office MIX and so on, there would be various problems caused by the computer configuration of the training objects, and it would take much time for the training teachers to explain these problems. And the teachers knew it was a waste of time, the problem was that the training objects payed more attention on how to install and use the software. After the training class was over, many teachers complained that they only installed two soft-wares during the two-day training, and the training cost would be better to pay for a high-configuration computer by their school. And they worried that even though they took much time 
learning how to produce MOOC, which might not be suit in their schools. In my opinion, software production was a need link in the training. But it was better to be practiced after class, and in class the training objects should pay more attention on the idea taught by the training teachers.

\section{The trend of the MOOC, Mini-class and flipped training class in college}

The problems mentioned in the training classes were inevitable in the development of the MOOC, mini-class and flipped class in college. As they are growing more and more mature, the problems will be solved. The following are my opinions about the trend of the MOOC, Mini-class and flipped training class of college.

\subsection{Classification of the training objects}

Since MOOC, mini-class and flipped class are under developing, so are the training class. In the predictable future, there will be born many experts and scholars in this field, and the training will be focused on one certain training object and specifically organized.

\subsection{The introduction of the MOOC and flipped class focusing on one certain course}

As colleges pay more and more attention and put more and more investment in the MOOC, mini-class and flipped class, the nation will held more competitions. Therefore, there will emerge more and more and better excellent MOOC and mini-class. And the specific MOOC and flipped model class focusing on one certain course will be born.

\subsection{The detailization of training course}

With the popularization of the MOOC, mini-class and flipped class, more and more college teachers will notice them. The training teachers will get a deep understanding. And the training content will be more detailed and closer to the teaching practice and course production.

\section{Conclusion}

Class, class, or flip the classroom, is a kind of carrier, as the study of mass education and training platform application. Internet has given rise to a broad application background of classroom, class, class, turning the classroom, adapted to the demand of the new generation, influence of course in Chinese colleges and universities. As the education teaching reform, "Internet +" training workshops, but its development also appeared some problems, such as the training object no pertinence, focus on training teachers taught in the related concept, etc. So for the "Internet +" under the background of mu class, class, flip the classroom teaching, on the one hand, must face the "Internet + " with an open attitude, by the network engine to bring new life to education class; , on the other hand, to stick to solid value, alert to the "technology first" and "subject participation teachers is low," not violating education laws, don't ignore the reality conditions, otherwise will also make the mistake exquisite course and university of the network. Open and stick to classroom teaching, should be in the service of the basic goal of education.

As a line of teacher teaching, as long as it is can promote the teaching of new things, should study and take advantage of in a timely manner. To class, the class and flip for after the combination of classroom teaching, according to different training object specific demonstration, refine the training, improve the teachers' basic quality and professional functions, such as the teacher wants to be good to guide discussion, some of course more difficult to understand the knowledge, by watching video alone is not enough, need further close to the teaching practice, and the students discussed repeatedly, and realize the process of teaching is learning.

\section{References}

[1] Wang QY. The real meaning and application of MOOC, mini-class and flipped class [J]. Shanghai Research on Education, 2014(08).

[2] Song T, Lin MS, Zhang XY. The application of flipped class under the "mini-class" circumstance [J]. Software Guide, 2014(09). 
[3] Yi QH. The flipped class and teaching structure in MOOC [J]. Modern Educational Technology, 2015(04).

[4] Xie GL. The features and advantages of "six highs" and "seven news" of the MOOC [J]. Journal of Lanzhou Institute Education, 2015(10).

[5] Xie GL. The five relationship analysis of the MOOC, flipped class, mini-class and mini-vedio [J]. Education Scientific, 2015(05). 